\title{
The impact of adoption of conservation agriculture on smallholder farmers' food security in semi-arid zones of southern Africa
}

\author{
Nelson Mango ${ }^{1^{*}}\left(\mathbb{D}\right.$, Shephard Siziba ${ }^{2}$ and Clifton Makate
}

\begin{abstract}
Background: In southern Africa, conservation agriculture (CA) has received a lot of research and promotional support from various organizations in the past decades. Conservation agriculture is largely promoted as one of the few win-win technologies affordable to farmers, in the sense that potentially it improves farmers'yields (in the long term) at the same time conserving the environment. This is because conservation agriculture reduces nitrogen loss in the soil, promotes water and soil conservation and improves agronomic use efficiency of applied nutrients. However, some concerns have been raised over the feasibility of conservation agriculture on smallholder farms given constraints imposed by the biophysical and institutional realities under which smallholder farmers operate. The main aim of this study is to answer the question whether conservation agriculture is resulting in tangible livelihood outcomes to smallholder farmers. The counterfactual outcome approach was used to estimate ex post impact of conservation agriculture adoption on one of the key livelihood outcomes_-food security.

Results: The study that utilized a data set covering 1623 households in Zimbabwe, Malawi and Mozambique found no significant impact of conservation agriculture adoption on Food Consumption Score of farmers in Zimbabwe and Malawi. Possible reasons for the insignificant of CA impact on food security in Zimbabwe and Malawi could include the small land areas currently devoted to CA, and the failure to implement the full complement of practices necessary to set off the biophysical process that are expected to drive yield increases. In Mozambique, conservation agriculture significantly improved the Food Consumption Score for farmers exposed to the technology. A possible reason for effectiveness of CA in Mozambique could be due to the fact that often CA is being promoted together with other better cropping management practices such as timely weeding and improved seed varieties, which are poorly practiced by the generality of farmers in a country just emerging from a war period.

Conclusion: This paper provides one of the few ex post assessments of the impact of conservation agriculture adoption on household livelihood outcomes_-food security. Given the mixed findings, the study suggests that conservation agriculture farmers in the three countries need to be supported to adopt a value chain approach to conservation agriculture. This entails the introduction of commercial or high-value crops in the conservation agriculture programmes, value addition on farmers produce, access to the necessary support services such as markets for seed, fertilizer, herbicides and equipment as well as reliable extension. We believe that under such circumstances conservation agriculture can effectively reduce food insecurity and poverty in the medium to long term.
\end{abstract}

Keywords: Conservation agriculture, Impact assessment, Adoption, Household food security, Southern Africa

\footnotetext{
*Correspondence: nelsonmango16@gmail.com

${ }^{1}$ International Centre for Tropical Agriculture (CIAT), P.O. Box MP 228, Mt

Pleasant, Harare, Zimbabwe

Full list of author information is available at the end of the article
} 


\section{Background}

\section{Introduction}

Southern Africa region is an area typical of many countries in Africa where continued threats to the world's land resources are compounded by the need to raise food production and reduce poverty [1]. In this region, agriculture continues to be a strategic sector in the development of most of its countries. It forms the backbone of the economies of southern African countries by contributing $35 \%$ of the gross domestic product, offers $70-80 \%$ employment, provides about 30\% foreign exchange earnings and provides livelihoods to over $70 \%$ of smallholder farmers who constitute the bulk of the food producers $[1,2]$. Despite this pivotal role of agriculture, the southern African countries seem to have been bypassed by the Green Revolution because deepening hunger and abject poverty continue to impede the development prospects in much of sub-Saharan Africa in the twentyfirst century with over 50 million people in this region facing food insecurity and 25 million living in absolute poverty [2]. The numbers of malnourished children and people living below the poverty datum line are exponentially escalating [3], and this can potentially reduce the chances of the sub-Saharan region to meet sustainable development goals of ending poverty and hunger by 2030 . Although there are multiple dimensions to the problem of increased food insecurity, the fundamental cause is declining staple food production [4]. The reduced yields of important food crops are attributed to a number of causes that include: use of rudimentary farming practices, the low productive capacity of the heavily nutrient-mined sandy soils, increased frequency and intensity of cyclical droughts and the low input nature of the conventional farming systems in the region $[5,6]$. This host of production constraints coupled with the lack of incentives to smallholder farmers for engaging in optimal land management policies that would speed up the need for technological change is propelling massive land degradation leading to low agricultural productivity and consequently increased food insecurity [7]. Farming systems that are characterized by smallholder farms have so far been displayed low propensity to invest in improved agricultural technologies [8-10]. A fundamental problem that has been occurring silently over the years is the eroding of the productive capacity of soils. With little replenishing, in terms of organic and inorganic fertilizers, the soils have become depleted of minor and major nutrients necessary for crop production. The poor smallholder farmers of sub-Saharan Africa have the lowest usage rate of inorganic fertilizers in the world $[11,12]$. Furthermore, very few farmers use farming practices that physically conserve the soil, and as a result, farmers are trapped in a vicious circle of poverty and hunger as the soils continue to degrade unabated.

\section{Conservation Agriculture in southern Africa}

An analysis of agricultural performance in southern Africa shows that growth in food production has lagged behind population growth since the 1970s. Overall per capita food production including cereals and livestock declined from the 1970 through the 1990s [13]. During this era, conservation agriculture (CA), a farming approach that aims to reduce soil degradation and conserve soil moisture, was necessitated by the need to improve staple crop production in southern Africa [14, 15]. It was purely based on indigenous knowledge, which was then overlooked but is now gaining ground and is being promoted by scientists $[16,17]$.

A suite of practices fall under conservation agriculture, but reduced tillage and mulching are the main ones targeted to farmers in southern Africa [4, 15]. Three important principles underpin CA: (1) minimal soil disturbance, (2) permanent soil cover and (3) crop rotations [18, 19]. Minimum soil disturbance and permanent soil cover help in improving soil organic matter content, reducing water run-off due to increased infiltration, as well as increased soil biological activity [18]. Use of mulch is particularly important for infiltration and reduction in evaporation. This is especially in southern Africa where aridity is predicted to increase the effects of climate change [20]. Crop rotations prevent pests and disease carry-over as well as improving soil fertility when legumes are used.

The above-perceived benefits of CA have led to concerted efforts to promote it as a panacea for land degradation in southern Africa by the Food and Agricultural Organization (FAO), international research institutes, governments, non-governmental organization and national research institutions since the mid-1980s [21]. Even though CA has been successfully implemented in fertile soils in some parts of the world such as southern America, its performance on degraded soils in southern Africa remains unclear $[4,16]$.

There are dotted evidences so far of positive yield effects of $\mathrm{CA}$ in southern Africa, but these are largely coming from experimental plots [22, 23]. At the farm level, one of the immediate and key livelihoods outcome expectations is improved food security [24]. The biophysical transformations that are occasioned by practicing conservation agriculture are expected to result in sustained increase in crop yields [25]. However, caution must be exercised against the belief in CA as a "magic bullet" to a plethora of challenges associated with poor performance of agriculture in sub-Saharan Africa (SSA) 
$[15,26]$. A critical analysis about CA's ability to reverse the negative effects of conventional and traditional agricultural practices has for a long time been overlooked [15]. The adoption literature warns that if CA fails to materialize in tangible benefits that are at the fore of farmers' interest, such as increased food or income, prospects of its widespread adoption are low [27, 28]. Furthermore, CA successes in southern Africa are based on limited on-farm trials rather than complete adoption by farmers [26]. The unique conditions of smallholder farmers entail a different reception of CA in southern Africa and other developing countries. On the other hand, there is the argument that lack of published works on CA adoption in southern Africa leads to wrong conclusions about low adoption rates [29]. Literature on adoption of new technologies shows that socio-economic variables such household demographic attributes (e.g. age, gender and education) are among the key factors accounting for the differential adoption of CA among smallholder farmers $[4,30,31]$.

This study is based on a very extensive sample (1623) of smallholder farmers in three southern African countries of Zimbabwe, Malawi and Mozambique, and applying the latest impact assessment methodology empirically evaluates whether the use of conservation agriculture practices is making any improvement on the food security situation of farmers. This paper makes valuable addition to the literature, given the current heated debated in the literature on whether conservation agriculture works at all for smallholder farmers [15] and the scarcity of empirical work evaluating impact of $\mathrm{CA}$ on farmer livelihoods in southern Africa.

\section{Methods}

The study aims to attribute food security outcomes of farmers to adoption of conservation agriculture practices. The study is based on an extract of 1623 households interviewed during the Forum for Agricultural Research in Africa (FARA) sub-Saharan Africa Challenge Programme (SSA CP) end-line survey. The data were collected through questionnaire survey from a stratified random sample of farmers in Zimbabwe, Malawi and Mozambique. The section that follows briefly describes the research area, methods used to select the population sample, measures for food security and the econometric approaches used to establish causality between food security and CA use.

\section{The research area}

This study was conducted in selected areas of Zimbabwe-Mozambique-Malawi Pilot Learning Site (ZZM PLS) where International Centre for Tropical Agriculture (CIAT) under the sub-Saharan Africa Challenge
Programme has been implementing conservation agriculture practices since 2008. The ZMM Pilot Learning Site is a $274,000 \mathrm{sq} \mathrm{km}$ transect corridor running through north-east Zimbabwe, central Mozambique and southern Malawi. The ZMM PLS is dominated by the maize-mixed farming system. Other crops include tobacco and cotton. Sandy soils dominate the region, and the mean annual rainfall ranges between 600 and $750 \mathrm{~mm}$.

\section{Socio-economic environment of the research area}

Principal livelihoods are based on maize, tobacco, cotton, grain legumes, small ruminants and poultry and off-farm work activities. The maize-mixed system is currently in crisis because smallholder farmers have reduced the levels of use of science-based inputs, resulting from shortages of seed of improved varieties, fertilizers and agrochemicals and the high input-to-output price ratios. There are also problems of declining farm sizes and draught animal ownership; reduced labour supply due to HIV/AIDS; and falling migrant remittances. Soil fertility is declining, yields are falling and smallholder farmers are reverting to extensive production practices. This is resulting in mutually self-reinforcing mechanisms of increasing land degradation and, in turn, accelerating poverty and food insecurity. Drought and market volatility result in vulnerability, thereby reinforcing the vicious cycles of poverty. Despite the current crisis, there exist significant opportunities for long-term agricultural growth and high potential for poverty reduction. In the more densely populated areas with better services, strategies include intensification and diversification out of maize into higher-value cash crops such as vegetables and livestock combined with increasing off-farm income activities with strong linkages to agriculture. Implementation of these strategies depends on productive and profitable technologies for improved soil fertility management, conservation agriculture, integrated pest management (IPM), private sector investment for the development of viable input and output markets and farmers collective action (bulk buying, rotational savings, joint marketing and rural microfinance institutions). Diversification could also involve in the development of low-lying areas for irrigated or rain-fed vegetable production. In the low population density areas, priorities include area expansion and intensification through zero tillage, conservation farming, grain legumes integration, farmer-based multiplication of seeds and planting materials, and community-based land tenure reform. The principal challenge against which ZMM PLS project is utilizing Integrated Agricultural Research for Development (IAR4D) hinges around the need to reduce vulnerability through improved soil, water and nutrient use, 
intensification, diversification and improved functioning of markets and value chains.

\section{Sample population}

In this paper, we use a quasi-experimental design to compare outcomes under intervention (CA practicing households) and under non-intervention (non-CA practicing households). This involves experimental districts, which receives the treatment, and a control group, which do not receive treatment. Randomization under ideal conditions allows mean program impact to be assessed through simple comparisons of outcomes for treated and control groups [32]. The districts were stratified on the basis of market access and agro-climatic potential. For each intervention (CA treatment) district, there is one control district (nonCA), which was selected using stratified random sampling method. In the intervention district, five villages were then selected using stratified random methods. From the control district, five clean villages were also selected using stratified random sampling techniques. "Clean" villages generally refer to villages in which there is absence or very minimal level of any agriculture developmental intervention in the last 2-5 years. In each of the selected villages, ten households were randomly selected for monitoring and impact evaluation. The objective of the programme is to evaluate whether or not conservation agriculture has more livelihood impact (food security) in the intervention district relative to the counterfactual districts.

\section{Conceptualizing food security}

Food security in this paper is conceptualized as a position in which households have physical and economic accesses to adequate, safe and nutritious food to cater for their needs and preferences for a healthy life [33-35]. As highlighted in the paper earlier, IAR4D is expected to improve farm productivity, incomes and food security through promoting an interconnected network of actors in agricultural value chains. The cohesive nature of relationships in value chains improves the prospects of improving adoption of sustainable farming practices (technologies and methods) such as CA, access to production and market information among farming households just to mention but a few benefits. CA adoption has been widely promoted targeting the improvement in productivity in almost similar farming systems in the three countries. Increased crop productivity of farmers transform to enhancement in availability and access to food and surplus for sale $[24,35]$. This indicates that adoption of CA can have a direct and positive influence on household Food Consumption Scores ceteris paribus. In addition, household Food Consumption Scores can also be improved indirectly by CA through purchase of other essential food stuffs from income obtained after selling surplus crop outputs. Hence, we expect adopters of CA in all the studied areas to be better off in terms of food security using Food Consumption Scores as proxy measure for food security.

\section{Measuring food security}

Food security can be measured at various scales: regional, national, household and individual levels. In our case, we focus at the household level. A number of indicators are used to measure food security at household level, and these commonly include: the Household Dietary Diversity Score (HHDS); Copying Strategy Index (CSI) and the Food Consumption Score (FCS). The HHDS indicates the diversity of the dietary intake of a household; the CSI captures the severity of the strategy a household resorts to in copying with periods on food shortages; the FCS shows the quantity and quality of food actually consumed by a household. The suitability of each of these indicators depends on the given food shortage situation and intend use of the information. For example, for the purpose of a quick assessment under an emergency relief situation, the CSI may be more appropriate. In our case, we were concerned about both the quality and quantity consumed by households; hence, the FCS was a more suitable indicator of food security. The FCS was computed in accordance with guidelines provided by Emergency Food Security Assessment Handbook [36, 37]. The FCS is designed to reflect the quantity and quality of people's diet at household level. A composite score is derived from a weighted sum based on the food type and frequency of consumption during a 7-day period.

\section{Measuring impact}

To conceptualize and measure the impact, the study adopts the potential outcomes framework following earlier work [38-40]. According to this framework, impact (treatment effect) can be defined as the outcome for exposure (participation) minus the outcome for non-exposure (non-participation)- $\left(y_{1}-y_{0}\right)$. In our specific case, it is the difference in Food Consumption Score for use and non-use of CA. Because it is impossible to observe both an outcome and counterfactuals for the same individual, this approach relies on different individuals to estimate treatment effect. Because of the selection biases, treated farmers and non-treated farmers tend to be systematically different sub-samples. The inherent challenge of impact evaluation is therefore that of isolating the effect of the treatment from other factors and potential selection biases [41]. One of the often used means of dealing with selection bias and achieving statistically comparable groups utilizes the two key assumptions of conditional independence and overlap. Conditional independence assumption states that given a set of observable covariates $X$ that are not affected by 
treatment; potential outcomes $Y$ are independent of treatment assignment $T$. This means that $X$ must account for factors influencing exposure such that after controlling for these, the effect of adopting CA can be obtained free of selection bias. The overlap assumption requires that for all possible values of $X$, there are both treated and untreated units. Researchers term conditional independence and overlap as "strong ignorability" [38].

In this study, the average treatment effect (ATE) was estimated using the nearest-neighbour matching (NNMATCH) approach. This approach imputes the missing potential outcomes for the untreated group using average outcomes for individuals with similar observed characteristics, based on covariates $X$.

\section{Results and discussion}

\section{Adoption of conservation agriculture}

Table 1 summarizes the number of farmers covered by the survey and the incident of CA adoption across the three countries. Use of conservation agriculture was highest in Zimbabwe where about a third of the farmers (35\%) reported its use. This was followed by Mozambique (13.6\%), and Malawi (6.7\%) had notably much lower adoption rate. These figures seem consistent with the time period of CA promotion: CA promotion started much earlier in Zimbabwe compared to the

Table 1 Sample distribution

\begin{tabular}{lcc}
\hline Country & Sample size & \% using CA \\
\hline Malawi & 550 & 6.7 \\
Mozambique & 425 & 13.6 \\
Zimbabwe & 653 & 35.4 \\
Total & 1623 & 19.8
\end{tabular}

other countries. Overall with an average adoption rate of $19.8 \%, \mathrm{CA}$ is a relatively new technology still to diffuse to majority of the farmers in the sub-region.

\section{Socio-economic comparison of CA and non-CA farmers}

Table 2 shows a comparison of CA and non-CA farmers in terms of some selected socio-economic attributes of households. The mean Food Security Scores of farmers in the three countries ranging from 33 to 39 fall in the borderline and susceptible food consumption bracket according to World Food Programme (WFP). In Zimbabwe CA farmers had significantly $(P<0.1)$ lower FCS than non-CA farmers, while in Mozambique CA farmers were significantly more food secure than their counterparts; in Malawi, differences were not statistically significant.

Other notable differences between $\mathrm{CA}$ and non-CA farmers were observed for gender of household head in Mozambique (more female-headed CA households); access to arable land in Zimbabwe (non-CA farmers had larger land sizes); cultivated land size in Zimbabwe and Mozambique (in both countries, CA farmers cultivated smaller land parcels). For all other household characteristics, head age, household size, number draft cattle owned, ox-plough ownership, mobile phone ownership and crop income of CA and non-CA farmers were not different. Statistics showing a socio-economic comparison of CA and non-CA farmers in the three studied countries are presented in Table 2.

\section{Impact of CA adoption on FCS}

Table 3 shows the estimated impact of CA adoption on food security. Three parameters ATE, ATE1 and ATE0 have been computed using the NNMATCH module of

Table 2 A socio-economic comparison of CA and non-CA farmers

\begin{tabular}{|c|c|c|c|c|c|c|c|c|c|}
\hline \multirow[t]{2}{*}{ Country } & \multicolumn{3}{|c|}{ Zimbabwe } & \multicolumn{3}{|l|}{ Malawi } & \multicolumn{3}{|c|}{ Mozambique } \\
\hline & Non-CA & $\mathrm{CA}$ & $T$ test $(\operatorname{Pr}(T>t))$ & Non-CA & CA & $T$ test $(\operatorname{Pr}(T>t))$ & Non-CA & CA & $T$ test $(\operatorname{Pr}(T>t))$ \\
\hline Food Consumption Score & 35.16 & 33.06 & 0.086 & 36.42 & 36.60 & 0.527 & 35.94 & 39.21 & 0.088 \\
\hline Head age (years) & 51.63 & 52.19 & 0.647 & 42.29 & 44.19 & 0.740 & 46.06 & 45.04 & 0.337 \\
\hline Gender (prop. male) & 0.71 & 0.72 & 0.631 & 0.85 & 0.88 & 0.640 & 0.91 & 0.85 & 0.094 \\
\hline Household size & 5.89 & 5.90 & 0.506 & 5.18 & 4.88 & 0.237 & 7.23 & 8.38 & 0.973 \\
\hline Draft cattle & 1.39 & 1.21 & 0.128 & 0.02 & 0.00 & 0.354 & 0.58 & 1.52 & 0.997 \\
\hline Mobile phone (prop.) & 0.15 & 0.16 & 0.567 & 0.17 & 0.13 & 0.300 & 0.11 & 0.31 & 0.998 \\
\hline Ox-plough (prop.) & 0.86 & 0.82 & 0.248 & 0.02 & 0.00 & 0.353 & 0.05 & 0.09 & 0.832 \\
\hline Arable land (acres) & 8.92 & 7.65 & 0.005 & 2.64 & 2.78 & 0.655 & 4.05 & 4.05 & 0.503 \\
\hline Cultivated land (acres) & 6.08 & 5.16 & 0.009 & 2.43 & 2.64 & 0.712 & 3.23 & 2.49 & 0.026 \\
\hline Crop income (Usd) & 124.60 & 114.32 & 0.353 & 75.10 & 83.99 & 0.571 & 66.80 & 125.83 & 0.956 \\
\hline
\end{tabular}

Food consumption profiles as given in [36,37] and considered in this study are as follows: $0-21$ is given as poor; $21.5-35$ is given as borderline consumption; and >35 is given as acceptable consumption. Average Food Consumption Scores in the study sites ranged between 33.06 and 39.21 , which can be classified as borderline to acceptable levels 
Table 3 Impact of CA adoption on Food Consumption Score

\begin{tabular}{|c|c|c|c|c|c|c|c|c|c|}
\hline \multirow{2}{*}{$\begin{array}{l}\text { Country } \\
\text { Parameter }\end{array}$} & \multicolumn{3}{|c|}{ Zimbabwe } & \multicolumn{3}{|l|}{ Malawi } & \multicolumn{3}{|c|}{ Mozambique } \\
\hline & Coef. & SE & $P>|Z|$ & Coef. & SE & $P>|Z|$ & Coef. & SE & $P>|Z|$ \\
\hline ATE & -2.050 & 2.080 & 0.324 & -0.194 & 2.714 & 0.943 & 0.944 & 2.777 & 0.734 \\
\hline ATE1 & -2.050 & 2.080 & 0.324 & -0.030 & 3.030 & 0.992 & 5.486 & 3.232 & 0.090 \\
\hline ATEO & -2.210 & 1.920 & 0.249 & -0.205 & 2.749 & 0.941 & 0.241 & 2.840 & 0.932 \\
\hline
\end{tabular}

STATA and employing the following variables as balancing covariates: head age, gender and household size. ATE is the average treatment effect on a randomly selected individual in the population, while ATE1 is the effect of treatment on a person randomly selected from the exposed sub-population, and ATE0 is the effect on those not exposed yet.

In Zimbabwe and Malawi, negative effects of CA adoption on food security were observed though these were not statistically significant. For example, in Zimbabwe CA adoption was estimated to result in a reduction (ATE1) of 2.05 in the FCS among farmers who were using CA. Positive results were observed in Mozambique where $C A$ adoption resulted in an improvement in the FCS by 5.486 among CA users (ATE1), and this effect was statistically significant $(P<0.1)$. Possible reasons for the insignificant of CA impact on food security in Zimbabwe and Malawi could include the small land areas currently devoted to $\mathrm{CA}$, and the failure to implement the full complement of practices necessary to set off the biophysical process that are expected to drive yield increases. For example, farmers due to constraints imposed by the biophysical, institutional and socio-economic environment often fail to achieve meaningful residue retention and/ or incorporate herbicides to control weeds [4]. A possible reason for effectiveness of $\mathrm{CA}$ in Mozambique could be due to the fact that often CA is being promoted together with other better cropping management practices such as timely weeding and improved seed varieties, which are poorly practiced by the generality of farmers in a country just emerging from a war period.

Overall, the lack of stout, persistent and positive impacts of CA adoption across the three studied countries could be attributed to selective adoption of CA principles common in the region as highlighted by scientists [15], and the shorter time period (from inception of IAR4D activities to end-line survey data collection) considered to conceive the impact of CA on farming households in this study. More so, the lack of persistent results is plausible given the differences among the three studied countries in other various conditions not captured in the data set (e.g. macroeconomic conditions and differences in agricultural extension systems) that may affect and explain the differences in CA adoption.
Studies have shown that farmers in Africa do not adopt all the relevant principles of CA adoption due to different constraining factors including labour requirements, insufficient resources to grow high-value crops and limited access to productive inputs [42-44]. Also important to note is the fact that institutional links expected to reduce time lags between technological development and dissemination and final uptake by farmers need time to materialize [35]. Since CA was being promoted in a new paradigm "IAR4D," it is possible that weak cohesion among multiple stakeholders and difficulties in adapting to the new approach can explain limited impacts of CA in studied sites.

\section{Conclusion}

This paper provides one of the few ex post assessments of the impact of CA adoption on household livelihood outcomes-food security. The study employed the counterfactual outcomes framework to isolate the effect of CA on household Food Consumption Score. Results show that in Zimbabwe and Malawi CA had no impact on FCS, while in Mozambique a positive and significant impact was observed. Possible reasons for the insignificant of CA impact on food security in Zimbabwe and Malawi could include the small land areas currently devoted to $\mathrm{CA}$, and the failure to implement the full complement of practices necessary to set off the biophysical process that are expected to drive yield increases. Also, tobacco plays a very big role in farmers' livelihoods in these two countries. Farmers who grow tobacco do not use CA in tobacco fields. A possible reason for effectiveness of CA in Mozambique could be due to the fact that often $\mathrm{CA}$ is being promoted together with other better cropping management practices such as timely weeding and improved seed varieties, which are poorly practiced by the generality of farmers in a country just emerging from a war period. Therefore, there is a need to identify constraints that are limiting the transformation of CA biophysical processes into tangible livelihoods outcomes key of which is increased food security. Also, it may be interesting for future research to ascertain the impact of CA adoption on livelihood outcomes in studied countries taking note of the actual CA principles adopted by farmers. This could add value and improve understanding on 
livelihood impact aspects of CA in the region. The studies have shown differential adoption of CA principles in Africa of which the practice leads to less than intended benefits to farmers. Understanding constraints that could be limiting adoption of all the CA principles by farmers can inform proper CA impact evaluation. Despite all these, we would like to propose as a matter of policy that a value chain approach should be used to ensure sustainability and profitability of CA to farmers. Governments in the region should include commercial and high-value crops into the CA programme, add value to farmers produce and link them to lucrative markets so that they can benefit from the high yields that accrue as a result of adopting CA technologies.

\begin{abstract}
Abbreviations
ATE: average treatment effect; CA: conservation agriculture; CIAT: International Centre for Tropical Agriculture; EFSA: Emergency Food Security Assessment; FARA: Forum for Agricultural Research in Africa; FAO: Food and Agriculture Organization of the United Nations; FCS: Food Consumption Score; IAR4D: Integrated Agricultural Research for Development; IPM: integrated pest management; NNMATCH: nearest-neighbour matching approach; STATA: Data Analysis and Statistical Software; SSA: sub-Saharan Africa; SSA CP: Sub-Saharan Africa Challenge Programme; ZZM PLS: Zimbabwe-Mozambique-Malawi Pilot Learning Site; WFP: World Food Programme.
\end{abstract}

\section{Authors' contributions}

NM coordinated the implementation of the study, supervised the design of the study and revised the manuscript; SS designed the study, analysed data and drafted the manuscript; CM supervised the data collection, data entry and cleaning and did literature review. All the authors read and approved the final manuscript.

\section{Author details}

${ }^{1}$ International Centre for Tropical Agriculture (CIAT), P.O. Box MP 228, Mt. Pleasant, Harare, Zimbabwe. ${ }^{2}$ Department of Agricultural Economics, University of Zimbabwe, P.O. Box MP 167, Mt. Pleasant, Harare, Zimbabwe.

\section{Acknowledgements}

The researchers acknowledge the International Centre for Tropical Agriculture (CIAT) that commissioned this study and enumerators from University of Zimbabwe, Lilongwe University of Agriculture and Natural Resources, Malawi and the National Institute of Agricultural Research of Mozambique. They also thank all reviewers for their comments and suggestions on earlier drafts of this article. Special thanks to Ms. Janine Thorne for editing the paper.

\section{Competing interests}

The authors declare that they have no competing interests.

\section{Availability of supporting data}

Data for this study can be obtained from CIAT Dataverse. Repository URL https://dataverse.harvard.edu/dataverse/CIAT.

\section{Consent for publication}

The authors give consent to the Journal of Agriculture and Food Security to publish and distribute this paper under the terms of the Creative Commons Attribution 4.0 International License (http://creativecommons.org/licenses/ by/4.0/), which permits unrestricted use, distribution and reproduction in any medium, provided that you give appropriate credit to the original author(s) and the source, provide a link to the Creative Commons licence, and indicate whether changes were made.

\section{Ethical approval and consent to participate}

The study was approved by the International Centre for Tropical Agriculture in collaboration with its partners, University of Zimbabwe, Lilongwe University of
Agriculture and Natural Resources, National Institute of Agricultural Research in Mozambique and considered exempt. Informed consent was obtained from all the participants. The authors have all the ethical approval and consent to take and participate in research paper writing and submission to any relevant journal from our organizations where we are working and posted.

\section{Funding}

This research was supported by funding from the International Fund for Agricultural Development (IFAD) through the Forum of Agricultural Research in Africa (FARA) to whom the authors express immense gratitude.

Received: 2 September 2016 Accepted: 12 March 2017

Published online: 23 March 2017

\section{References}

1. Kandji ST, Verchot L, Mackensen J. Climate change and variability in southern Africa: impacts and adaptation in the agricultural sector. Nairobi: Word Agroforestry Centre (ICRAF), United Nations Environment Programme (UNEP); 2006. p. 42.

2. Diao $X$, Hazell $P$, Thurlow J. The role of agriculture in African development World Dev. 2010;38(10):1375-83.

3. African Agricultural Technology Foundation (AATF). A new bridge to sustainable agriculture development in Africa. Inaugural Report Nairobi, Kenya. 2005.

4. Siziba S. Assessing the adoption of conservation agriculture in Zimbabwe's smallholder sector. PhD Thesis. Stuttgart, Germany: University of Hohenheim; 2008.

5. Arslan A, McCarthy N, Lipper L, Asfaw S, Cattaneo A. Adoption and intensity of adoption of conservation farming practices in Zambia. Agric Ecosyst Environ J. 2013;187:72-86. doi:10.1016/j.agee.2013.08.017.

6. Zingore S, Tittonell P, Corbeels M, Van Wijk MT, Giller KE. Managing soil fertility diversity to enhance resource use efficiencies in smallholder farming systems: a case from Murewa District, Zimbabwe. Nutr Cycl Agroecosyst J. 2011;90(1):87-103.

7. Zingore S. Exploring diversity within smallholder farming systems in Zimbabwe: nutrient use efficiencies and resource management strategies for crop production. PhD Thesis. Wageningen: Wageningen University. 2006.

8. Bekele W, Drake L. Soil and water conservation decision behavior of subsistence farmers in the eastern highlands of Ethiopia: a case study of the Hunde-Lafto area. Ecol Econ. 2003;46(3):437-51. doi:10.1016/ S0921-8009(03)00166-6.

9. Kassie M, Zikhali P, Manjur K, Edwards S. Adoption of organic farming technologies: evidence from semi-arid regions of Ethiopia. Environment for Development, EfD DP 09-01, January 2009.

10. Makate C, Wang R, Makate M, Mango N. Crop diversification and livelihoods of smallholder farmers in Zimbabwe: adaptive management for environmental change. SpringerPlus. 2016;5(1):1-18. doi:10.1186/s40064-016-2802-4.

11. Mwangi WM. Low use of fertilizers and low productivity in sub-Saharan Africa. Nutr Cycl Agroecosyst. 1996;47(2):135-47. doi:10.2134/agronj1977. $00021962006900010021 x$

12. Kelly V, Jayne T, Crawford E. Farmers' demand for fertilizer in sub-Saharan Africa. East Lansing, USA: Michigan State University; 2005.

13. Abalu G, Hassan R. Agricultural productivity and natural resource use in southern Africa. Food Policy. 1998;23(6):477-90.

14. Bolliger A. Is zero-till an appropriate agricultural alternative for disadvantaged smallholders of South Africa? A study of surrogate systems and strategies, smallholder sensitivities and soil glycoproteins. PhD Thesis. Copenhagen: University of Copenhagen; 2007.

15. Giller KE, Witter E, Corbeels M, Tittonell P. Conservation agriculture and smallholder farming in Africa: the heretics' view. Field Crops Res. 2009;114(1):23-34. doi:10.1016/j.fcr.2009.06.017.

16. Kaumbutho P, Gebresenbet G, Simalenga T. Overview of conservation tillage practices in east and southern Africa. In: Kaumbutho PG, Simalenga $\mathrm{TE}$, editors. Conservation tillage with animal traction. A resource book for the Animal Traction Network for Eastern and Southern Africa. Harare, Zimbabwe: ATNESA Publications; 1999.

17. Kassie M, Zikhali P, Manjur K, Edward S. Adoption of sustainable agriculture practices: evidence from a semi-arid region of Ethiopia. Nat Resour Forum. 2009;33:189-98. doi:10.1111/j.1477-8947.2009.01224. 
18. Dumanski J, Peiretti R, Benites J, McGarry D, Pieri C. The paradigm of conservation agriculture. Proc World Assoc Soil Water Conserv. 2006:P1:58-64.

19. Food and Agriculture Organization of the United Nations (FAO). Investing in sustainable agricultural intensification. the role of conservation agriculture. A framework for action. Rome, Italy: FAO Publication; 2008. Available at http://www.fao.org/ag/ca.

20. Lobell DB, Burke MB, Tebaldi C, Mastrandrea MD, Falcon WP, Naylor RL. Prioritizing climate change adaptation needs for food security in 2030 . Sci J. 2008;319(5863):607-610. http://www.sciencemag.org.

21. Twomlow S, Hove L, Mupangwa W, Patricia Masikati P, Nester Mashingaidze N. Precision conservation agriculture for vulnerable farmers in low-potential zones. In: Proceedings of the workshop on increasing the productivity and sustainability of rainfed cropping systems of poor, smallholder farmers. Tamale, Ghana; 2008.

22. Thierfelder C, Wall P. Investigating conservation agriculture (CA) systems in Zambia and Zimbabwe to mitigate future effects of climate change. Crop Improv. 2010;24(2):113-21. doi:10.1080/15427520903558484.

23. Thierfelder C, Matemba-Mutasa R, Rusinamhodzi L. Yield response of maize (Zea mays L.) to conservation agriculture cropping system in southern Africa. Soil Tillage Res. 2015;146:230-42. doi:10.1016/j. still.2014.10.015

24. Nyikahadzoi K, Siziba S, Mango N, Mapfumo P, Adekunle A, Oluwole F. Creating food self reliance among the smallholder farmers of eastern Zimbabwe: exploring the role of Integrated Agricultural Research for Development. Food Secur. 2012;4(4):647-56. doi:10.1007/ s12571-012-0218-8.

25. Erenstein OC. The economics of soil conservation in developing countries: the case of crop residue mulching: PhD Dissertation, Published by Mansholt Institute, Wageningen University [sn]. 1999.

26. Gowing J, Palmer M. Sustainable agricultural development in subSaharan Africa: the case for a paradigm shift in land husbandry. Soil Use Manag. 2008:24(1):92-9.

27. Cary JW, Wilkinson RL. Perceived profitability and farmers'conservation behaviour. J Agric Econ. 1997;48(1-3):13-21. doi:10.1111/j.1477-9552.1997.tb01127.x.

28. Pannell D. Social and economic challenges in the development of complex farming systems. Agrofor Syst J. 1999;45(1-3):395-411. doi:10.10 23/A:1006282614791.

29. Mazvimavi K, Twomlow S, Belder P, Hove L, et al. An assessment of the sustainable uptake of conservation farming in Zimbabwe: global theme on agroecosystems report no. 39. International Crops Research Institute for the Semi-Arid Tropics: Bulawayo; 2008. p. 60.

30. Mazvimavi K, Marongwe LS, Musitini T, Ndlovu P. What influences spontaneous adoption of conservation farming in Zimbabwe: the case of ward 14, Masvingo District. A survey carried on behalf of ICRISAT and Ministry of Agriculture. Unpublished. 2009.

31. Chiputwa B. Two essays on maize intra-crop diversity and use of improved varieties. Unpublished MSc Thesis, University of Georgia, Athens, Greece. 2011
32. Binam JN, Abdoulaye T, Olarinde L, Kamara A, Adekunle A. Assessing the potential impact of Integrated Agricultural Research for Development (IAR4D) on adoption of improved cereal-legume crop varieties in the Sudan Savannah Zone of Nigeria. J Agric Food Inf. 2011;12(2):177-98.

33. Food and Agricultural Organisation of the United Nations (FAO). Declaration on world food security. Rome, Italy: FAO Publication; 1996.

34. Swindale A, Bilinsky P. Household Dietary Diversity Score (HDDS) for measurement of household food access: indicator guide. Washington: Academy for Educational Development, Food and Nutrition Technical Assistance Project; 2005

35. Mango N, Nyikahadzoi K, Makate C, Dunjana N, Siziba S. The impact of Integrated Agricultural Research for Development on food security among smallholder farmers of southern Africa. Agrekon J. 2015;54(3):107-25. doi:10.1080/03031853.2015.1084942.

36. World Food Programme (WFP). Food consumption analysis calculation and use of the food consumption score in food security analysis. Rome: United Nations; 2008

37. World Food Programme (WFP). Emergency Food Security Assessment Handbook, 2nd edn. Rome, Italy: WFP, Food Security Analysis Service; 2009.

38. Rosenbaum PR, Rubin DB. The central role of the propensity score in observational studies for causal effects. Biometrika. 1983:70(1):41-55. doi:10.1093/biomet/70.1.41.

39. Angrist JD, Imbens GW, Rubin DB. Identification of causal effects using instrumental variables. J Am Stat Assoc. 1996;91(434):444-55.

40. Heckman JJ, Vytlacil E. Structural equations, treatment effects, and econometric policy evaluation 1. Econometrica. 2005;73(3):669-738.

41. Khandker SR, Koolwal GB, Samad HA. Handbook on impact evaluation: quantitative methods and practices. Washington: World Bank Publications; 2009

42. Baudron F, Mwanza HM, Triomphe B, Bwalya M, Conservation agriculture in Zambia: a case study of southern province. African Conservation Tillage Network, Centre de Coopération Internationale de Recherche Agronomique pour le Dévelopment. Nairobi: Food and Agricultural Organization of the United Nations; 2007.

43. Shetto R, Owenya M. Conservation agriculture as practised in Tanzania: three case studies. African Conservation Tillage Network, Centre de Coopération Internationale de Recherche Agronomique pour le Développement. Nairobi: Food and Agriculture Organization of the United Nations; 2007.

44. Kaumbutho P, Kienzle J. Conservation agriculture as practised in Kenya: two case studies. African Conservation Tillage Network, Centre de Coopération Internationale de Recherche Agronomique pour le Développement. Nairobi: Food and Agriculture Organization of the United Nations; 2007

\section{Submit your next manuscript to BioMed Central and we will help you at every step:}

- We accept pre-submission inquiries

- Our selector tool helps you to find the most relevant journal

- We provide round the clock customer support

- Convenient online submission

- Thorough peer review

- Inclusion in PubMed and all major indexing services

- Maximum visibility for your research

Submit your manuscript at www.biomedcentral com/submit 